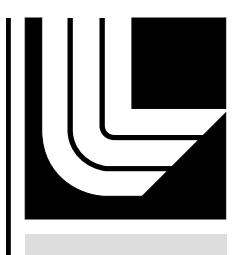

LAW RENCE LIVERMORE N A T IO N A L LABORATORY

\title{
UCRL-JRNL-227556
}

\section{The role of EBIT in X-ray laser research}

J. Nilsen

January 29, 2007

Canadian Journal of Physics 
This document was prepared as an account of work sponsored by an agency of the United States Government. Neither the United States Government nor the University of California nor any of their employees, makes any warranty, express or implied, or assumes any legal liability or responsibility for the accuracy, completeness, or usefulness of any information, apparatus, product, or process disclosed, or represents that its use would not infringe privately owned rights. Reference herein to any specific commercial product, process, or service by trade name, trademark, manufacturer, or otherwise, does not necessarily constitute or imply its endorsement, recommendation, or favoring by the United States Government or the University of California. The views and opinions of authors expressed herein do not necessarily state or reflect those of the United States Government or the University of California, and shall not be used for advertising or product endorsement purposes. 


\title{
The role of EBIT in X-ray laser research
}

\author{
Joseph Nilsen \\ Lawrence Livermore National Laboratory \\ P.O. Box 808, L-15 \\ Livermore, CA 94551-0808
}

Phone: 1-925-422-4766

FAX: 1-925-422-5102

jnilsen@1lnl.gov

52.38.-r Laser-plasma interactions

52.25.Os Emission, absorption, and scattering of electromagnetic radiation

52.70.-m Plasma diagnostic techniques and instrumentation

42.55.Vc X- and gamma-ray lasers

07.60.Ly Interferometers

29.30.Kv X- and gamma-ray spectroscopy

31.15.-p Calculations and mathematical techniques in atomic physics 
Abstract. Back in the early 1980's the X-ray laser program required a new level of understanding and measurements of the atomic physics of highly charged ions. The electron-beam ion trap (EBIT) was developed and built at Lawrence Livermore National Laboratory (LLNL) as part of the effort to understand and measure the cross sections and wavelengths of highly charged ions. In this paper we will discuss some of the early history of EBIT and how it was used to help in the development of X-ray lasers. EBIT's capability was unique and we will show some of the experimental results obtained over the years that were done related to X-ray lasers. As X-ray lasers have now become a table-top tool we will show some new areas of research that involve understanding the index of refraction in partially ionized plasmas and suggest new areas where EBIT may be able to contribute.

\section{Introduction}

In the early 1980's the X-ray laser became the topic of news articles because of a new application that would eventually be the primary motivation for X-ray laser research in the United States. Clarence Robinson wrote a 1981 Aviation Week article [1] that said that scientists from Lawrence Livermore National Laboratory (LLNL) had made a breakthrough in laser technology by demonstrating a compact laser device pumped by X-rays from a small nuclear detonation.

At LLNL the early 1980's was an exciting time for the X-ray laser program. LLNL was developing a large X-ray laser program to address the challenge presented by President Reagan to develop a missile defense system, know as "Star Wars" or SDI. As part of this program [2-4] LLNL succeeded in demonstrating the first X-ray laser in the early 1980's using a nuclear explosion to drive the X-ray laser. Later in the decade the first laboratory X-ray laser using Nelike Se driven by the large Novette ICF laser was demonstrated at LLNL [5].

The Soviet Union also took a strong interest in X-ray lasers. In 1987 they successful produced X-ray lasers driven by nuclear explosions that produced lasers with about $20 \mathrm{~kJ}$ of output at $39 \AA$ and $100 \mathrm{~kJ}$ of output at a wavelength of $28 \AA$. This is described in a 1997 article 
[6] written by E. N. Avrorin and colleagues at Chelyabinsk-70 that tells how the Soviet Union initiated a program to understand X-ray laser physics and evaluate the feasibility of making an Xray laser with the characteristics reported in the Aviation Week article. This was a time of intense competition between the United States and the Soviet Union. To facilitate the understanding and development of X-ray lasers at LLNL required a new level of understanding and measurements of the atomic physics of highly charged ions. The electron-beam ion trap (EBIT) was developed and built at LLNL as part of the effort to understand and measure the cross sections and wavelengths of highly-charged ions [7]. As an example of this need, the first laboratory X-ray laser using Nelike Se did not lase on the $3 p-3 s$ line at $182 \AA$, as expected, but instead lased on two other weaker lines at 206 and $209 \AA[5]$.

\section{Experiments before EBIT}

Prior to the creation of the first EBIT facility in Livermore, LLNL researchers traveled to large facilities such as the UNILAC at GSI Darmstadt to measure high-Z line positions as part of the effort to understand multi-electron QED effects in atomic physics in support of the X-ray laser effort. Dan Dietrich from LLNL spent a year from July 1985 in Europe based in Oxford and Paris. During that year he did experiments at GSI and various people from LLNL visited GSI to participate in those experiments. In the experiments at GSI $[8,9]$ the $n=3$ and 4 to $n=2$ resonance lines of Ne-like $\mathrm{Au}(Z=79)$ and $\mathrm{Bi}(Z=83)$ were measured with high precision and compared with our theoretical codes. One of the difficulties with the measurements was that the large Doppler shift associated with the multi-GeV UNILAC beam used to create the Ne-like ions resulted in experimental uncertainties that were comparable to the difference between theory and experiment. For example, looking at the position of the Ne-like $\mathrm{Au}\left(2 \mathrm{p}_{3 / 2}\right) 4 \mathrm{~d}_{5 / 2}(\mathrm{~J}=1) \rightarrow$ ground state transition, it was measured to be at $13802.8 \mathrm{eV}$ with an uncertainty of $8.9 \mathrm{eV}$. This line was calculated to be at $13809.7 \mathrm{eV}$. The calculation was $6.9 \mathrm{eV}$ higher energy than the measured value but the uncertainty of $8.9 \mathrm{eV}$ was larger than the difference between theory and experiment [8]. The notation $\left(2 \mathrm{p}_{3 / 2}\right)$ means a $2 \mathrm{p}$ hole in the closed $2 \mathrm{p}$ subshell.

While the GSI experimental uncertainties were reduced to about $2 \mathrm{eV}$ in the Bi experiments published in Ref. 9 these experiments motivated the creation of a local facility at LLNL that 
could measure more materials, more quickly, and with higher accuracy. A lot was learned in the GSI experiments and these experiments set the important precedent for publishing all the experimental results of the high-Z spectroscopy measurements.

The X-ray laser program was also helping to support spectroscopy measurements of the $\mathrm{n}=$ 3 to $\mathrm{n}=2$ lines of Ne-like Ag ions done at the Princeton Large Torus (PLT) Tokamak [10,11]. This work was part of the Ph. D. thesis of Peter Beiersdorfer who subsequently came to LLNL to work on EBIT for the next two decades.

At the same time as the GSI experiments the research of Donets [12] in the Soviet Union had captured the attention of many spectroscopists. He had taken the electron beam ion source (EBIS) concept and extended it to higher voltage and current so that it could produce almost fully stripped $\mathrm{Xe}(\mathrm{Z}=54)$ ions. The original EBIS devices had been used to create fully stripped ion sources for $Z<10$. The EBIS offered the potential to have a small laboratory-size alternative to using large accelerators for studying highly charged ions. Many researchers studied this work. There was a working EBIS device at Lawrence Berkeley Laboratory (LBL) that served as a training ground for many of the Livermore and Berkeley scientists. To meet the needs of the Xray laser program at LLNL two competing designs were put forth. An effort at Sandia-Livermore led by Bob Schmeider worked to create a Super-EBIS device [13]. This was designed to produce Ne-like $U$ ions and had a 1-m long super-conducting solenoid with an electron gun rated up to 80 $\mathrm{kV}$. At the same time, the group at LLNL led by Ross Marrs in collaboration with Mort Levine from LBL worked to create the first electron beam ion trap (EBIT) [7]. The original EBIT trapped the ions in a 2-cm long drift tube and operated up to $30 \mathrm{kV}$ and produced Ne-like $\mathrm{Au}$ ions. The big advantage of EBIT was that it was more compact than EBIS and the ions could be viewed directly in the trap. The EBIS concept produced more ions but they needed to be extracted from the source. In the end the EBIT technology proved to be more successful and was used by the X-ray laser program to do atomic physics measurements. EBIT has been a very valuable tool over the last 20 years. It enabled rapid response to important questions. The LLNL experimentalists no longer had to travel far distances and schedule beam time on other facilities. By controlling the voltage one could select a particular ionization stage to study with EBIT. With the low electron and ion temperatures in the trap very high-resolution spectroscopy could be 
done with EBIT. When the Ne-like $\operatorname{Ir}\left(2 \mathrm{p}_{3 / 2}\right) 4 \mathrm{~d}_{5 / 2}(\mathrm{~J}=1)->$ ground state transition was measured [14] with EBIT the experimental uncertainty for $\operatorname{Ir}(Z=77)$ was $0.33 \mathrm{eV}$ as compared with the 8.9 $\mathrm{eV}$ uncertainty measured for the same transition in Ne-like $\mathrm{Au}(\mathrm{Z}=79)$ at GSI.

\section{EBIT Experiments for X-ray laser research}

As part of the X-ray laser program at LLNL many laser-driven X-ray laser experiments were done at the NOVA 2-beam laser facility [15-17]. The Nova 2-beam facility was funded by the Defense Sciences Department to help understand X-ray laser physics and more than a decade of research was conducted. Over the half-decade from 1992 to the decommissioning of the Nova 2beam facility on November 14, 1997, EBIT was used to do many experiments [18 - 28] to support X-ray laser research. In this section we will describe some of the research that was pursued in support of the laboratory X-ray laser effort.

One of the original concepts proposed to create an X-ray laser involved resonant photopumping in which a strong emission line in one material would photo-pump a transition in a second material and create lasing. In many ways this is analogous to the flashlamp pumped Nd:YAG laser [29]. In the Nd:YAG laser a flashlamp with a broadband spectral output photopumps broad absorption bands in the $\mathrm{Nd}^{3+}$. The $\mathrm{Nd}^{3+}$ is a classic four-level system where the excited electrons in the absorption band quickly decay to a ${ }^{4} \mathrm{~F}_{3 / 2}$ metastable level that becomes the upper laser level. This lases by a $1.06 \mu \mathrm{m}$ transition to the ${ }^{4} \mathrm{I}_{11 / 2}$ lower laser level which quickly decays back to the ground state. For the X-ray laser scheme one replaces the broadband flashlamp with a strong narrow emission line. The lasing material then has a strong narrow absorption line where the excited electrons decay rapidly to a metastable upper laser state. The advantage of the photo-pumped system is that the power from a strong isotropic emission line can be converted into a laser line. One big challenge is finding a good resonance where the resonance is good to a few parts in $10^{4}$. Typically theoretical calculations are not adequate and EBIT was used to evaluate many of the proposed X-ray laser schemes before they were tried on NOVA.

An example of one resonant photo-pumped scheme [19] is to use the strong He- $\alpha$ line of Ar at $3.9491 \AA$ to drive the ground state to $\left(2 \mathrm{p}_{1 / 2}\right) 5 \mathrm{~d}_{5 / 2}(\mathrm{~J}=1)$ transition in Ne-like $\mathrm{Y}$ and then lase on 
the $\left(2 p_{1 / 2}\right) 3 p_{1 / 2}(J=0)$ to $\left(2 p_{1 / 2}\right) 3 s_{1 / 2}(J=1)$ transition at $155 \AA$, as shown in Fig. 1. The $\left(2 p_{1 / 2}\right)$ $5 d_{5 / 2}(J=1)$ state rapidly decays to the $\left(2 p_{1 / 2}\right) 3 p_{1 / 2}(J=0)$ upper laser state with a rate of 1667 $n \operatorname{nec}^{-1}$. The radiative decay rates $[R]$ are shown in Fig. 1 in units of nsec ${ }^{-1}$. The $\left(2 p_{1 / 2}\right) 3 p_{1 / 2}(J=0)$ upper laser state is metastable and is dipole forbidden for decay directly to the ground state. The $\left(2 \mathrm{p}_{1 / 2}\right) 3 \mathrm{~s}_{1 / 2}(\mathrm{~J}=1)$ lower laser state rapidly decays back to the Ne-like ground state with a rate of $5318 \mathrm{nsec}^{-1}$. Calculations [19] predicted gain of about $10 \mathrm{~cm}^{-1}$ for this laser line for an Y plasma with an ion density of $10^{19} \mathrm{~cm}^{-3}$ and a Ar He- $\alpha$ line with a pump strength of 0.001 photons per mode.

EBIT experiments were done to carefully measure the position of the Ar and Y lines. In this case the Ar He- $\alpha$ line (w in Fig. 2) at $3.94911 \AA$ was used as the reference line and the $45.08 \mathrm{~m} \AA$ separation between lines $\mathrm{w}$ and $\mathrm{z}$ was used to establish the dispersion. Lines $\mathrm{w}, \mathrm{x}, \mathrm{y}$, and $\mathrm{z}$ have the upper states $1 \mathrm{~s} 2 \mathrm{p}{ }^{1} \mathrm{P}_{1}, 1 \mathrm{~s} 2 \mathrm{p}^{3} \mathrm{P}_{2}, 1 \mathrm{~s} 2 \mathrm{p}^{3} \mathrm{P}_{1}$, and $1 \mathrm{~s} 2 \mathrm{~s}^{3} \mathrm{~S}_{1}$, respectively. The EBIT experiment measured the Ne-like $\mathrm{Y}$ line at $3.94849 \AA$ with an uncertainty of $0.11 \mathrm{~m} \AA$. The $\mathrm{Ar}$ and $\mathrm{Y}$ lines are only separated by $0.6 \mathrm{~m} \AA$ which is less than the $1.5 \mathrm{~m} \AA$ Doppler width of the He- $\alpha$ pump line at a $1000 \mathrm{eV}$ ion temperature. Therefore we expect a very good resonance. This scheme was not actually tried at NOVA because of the difficulty of making an Ar target.

Another scheme [20] that was tried on NOVA was to use the very strong $\left(3 \mathrm{~d}_{3 / 2}\right) 4 \mathrm{f}_{5 / 2}(\mathrm{~J}=1)$ to ground state transition $\left(\mathrm{f}_{\text {osc }}=6\right)$ in Ni-like $\mathrm{Pt}$ as the pump line to photo-pump the ground state to $\left(2 p_{1 / 2}\right) 4 d_{3 / 2}(J=1)$ line in Ne-like $R b$. This $\left(2 p_{1 / 2}\right) 4 d_{3 / 2}(J=1)$ state decays to the $\left(2 p_{1 / 2}\right) 3 p_{1 / 2}$ $(\mathrm{J}=0)$ upper laser state that then lases at $165 \AA$ to the $\left(2 \mathrm{p}_{1 / 2}\right) 3 \mathrm{~s}_{1 / 2}(\mathrm{~J}=1)$ lower laser state. EBIT measured the Ni-like Pt line at 2511.9(5) eV and the Ne-like Rb line at 2512.3(5) eV with the uncertainty in the last digit shown in parenthesis. The $-0.4 \mathrm{eV}$ difference between these lines makes a good resonance while theory had predicted a difference of $+2.5 \mathrm{eV}$ between the lines, which was not an adequate resonance. The Pt pumped $\mathrm{Rb}$ scheme was tried in a series of experiments on NOVA but no lasing was observed. Even though there was a good resonance it turned out to be difficult to create a strong Ni-like Pt pump line and efficiently couple it to the $\mathrm{Ne}-$ like $\mathrm{Rb}$ lasing plasma. Also, it was not possible to make a pure $\mathrm{Rb}$ target so $\mathrm{RbCl}$ targets were used and this further reduced the potential $\mathrm{Rb}$ gain. 
In the attempt to reach shorter wavelength several X-ray laser schemes were proposed that involved lasing on inner shell transitions. One such scheme [24] whose resonance was verified by EBIT involved using the $\mathrm{Ly}-\alpha_{1}$ line of $\mathrm{H}$-like $\mathrm{Na}$ at $10.0232 \AA$ to photo-pump the ground state to $\left(2 \mathrm{~s}_{1 / 2}\right) 4 \mathrm{p}_{3 / 2}(\mathrm{~J}=1)$ transition in Ne-like Co. The $\left(2 \mathrm{~s}_{1 / 2}\right) 4 \mathrm{p}_{3 / 2}(\mathrm{~J}=1)$ level rapidly decays to the $\left(2 \mathrm{~s}_{1 / 2}\right) 3 \mathrm{~s}_{1 / 2}(\mathrm{~J}=0)$ upper laser state that then lases at $83 \AA$ via a $2 \mathrm{p} 3 / 2$ to $2 \mathrm{~s} 1 / 2$ transtion to the $\left(2 p_{3 / 2}\right) 3 s_{1 / 2}(J=1)$ lower laser state. The lower laser state quickly decays back to the Ne-like ground state. Using EBIT the Ne-like Co $\left(2 \mathrm{~s}_{1 / 2}\right) 4 \mathrm{p}_{3 / 2}(\mathrm{~J}=1)$ to ground state transition was measured at 10.0222(11) $\AA$, making an excellent resonance with the Ly- $\alpha$ line. This scheme was particularly interesting because the SATURN machine at Sandia National Laboratory (SNL) could produce very strong Ly- $\alpha$ radiation [30]. We have never had the opportunity to try this scheme.

EBIT was used to verify when we did not have a good resonance so that we would not waste valuable resources at the NOVA facility doing experiments that had little chance of success. One example [26] of this was the idea that we could used the strong Ly- $\alpha_{2}$ line $(1727.7 \mathrm{eV})$ of H-like Al to photo-pump the ground state to $\left(3 \mathrm{~d}_{3 / 2}\right) 4 \mathrm{f}_{5 / 2}(\mathrm{~J}=1)$ transition of Ni-like $\mathrm{Er}(\mathrm{Z}=68)$ and enhance the gain of five Ni-like $4 d-4 p$ transitions (between 54 and $89 \AA$ ) that had already been

observed to lase from collisional excitation and also create a new laser line at $64.8 \AA$. Existing data in the literature made this resonance look promising but EBIT measured the Er line at 1725.9(3) $\mathrm{eV}$ which made the $\mathrm{Al}-\mathrm{Er}$ resonance differ by $1.8 \mathrm{eV}$ which is too large for a good resonance. The result was that this idea was never tried at NOVA or SATURN.

\section{X-ray lasers today}

Today X-ray lasers are created at table-top laser facilities such as the COMET laser facility at LLNL [31]. A typical X-ray laser is the Ni-like Pd laser that lases at $14.7 \mathrm{~nm}$ and is driven by a combination of a 2-J, 600-ps pre-pulse [17] and 5-J, 6-psec main pulse from an optical laser at $1.05 \mu \mathrm{m}$ that is focused into a 1.6-cm long by $140-\mu \mathrm{m}$ line onto a 1.2- $\mathrm{cm}$ long Pd slab target. An important application of X-ray lasers is to do X-ray laser interferometry of other plasmas to measure the two dimensional (2D) electron density distribution of these other plasmas [32]. 
In the course of doing interferometry measurements of many different types of plasmas we have observed some anomalous effects in our interferograms [33 - 38]. We should point out that the basic assumption of X-ray laser interferomtry is that the index of refraction of the plasma is due only to the free electrons and is therefore less than one. The index of refraction $\mathrm{n}$ can be written as $n=1-\left[\left(f_{1} N_{\text {ion }}\right) /\left(2 N_{\text {crit }}\right)\right]$ where $f_{1}$ is the optical constant of the plasma, $N_{\text {ion }}$ is the ion density and $\mathrm{N}_{\text {crit }}$ is the critical density of the plasma at that wavelength. At wavelength $\lambda$, $\mathrm{N}_{\text {crit }}=\pi /\left(\mathrm{r}_{0} \lambda^{2}\right)$ where $\mathrm{r}_{0}$ is the classical electron radius, $2.818 \times 10^{-13} \mathrm{~cm}$ [39]. If only the free electrons contribute to the index of refraction than $f_{1}$ is equal to $Z^{*}$, the number of free electrons per ion.

We have observed plasmas, such as Ag [38], with an index of refraction greater than one where the fringe lines in the interferometer bend the opposite direction than expected. We were able to explain this by considering the contribution of the bound electrons to the index of refraction. Figure 3 shows a calculation of the optical constant $f_{1}$ for a Ag plasma with an ion density of $10^{20} \mathrm{~cm}^{-3}$ at a temperature of $4 \mathrm{eV}$. For this case the average atom code [40] gives a $Z^{*}=2.02$, indicating the average charge state of the ion is doubly ionized. If the index of refraction is due only to the free electrons than the optical constant $\mathrm{fl}$ should equal $\mathrm{Z}^{*}=2.02$ and be independent of the photon energy. However one can see that this is not the case. In fact, when $\mathrm{f}_{1}$ goes negative the index of refraction becomes greater than one. The average atom code calculates the energy of the $4 \mathrm{~d}-4 \mathrm{f}$ absorption line at $29.3 \mathrm{eV}$ while the more sophisticated multiconfiguration Dirac-Fock (MCDF) code [41] has the strong 4d-4f line at $25.5 \mathrm{eV}$. Using data from experiments done in doubly ionized Sn plasmas we had to shift the MCDF calculations by $+3 \mathrm{eV}$ to agree with the experimental data [38]. This entire regime of a few times ionized plasmas at mid to high- $Z$ is an area where there is very little experimental data yet the accurate calculation and explanation of X-ray optical constants depends on knowing the line positions accurately. This is a regime where even knowing the line positions to $1 \%$ would be a tremendous improvement. Maybe EBIT can be used to measure these warm partially ionized plasmas.

\section{Conclusion}

Back in the early 1980's the X-ray laser program required a new level of understanding and measurements of the atomic physics of highly charged ions. The electron-beam ion trap (EBIT) 
was developed and built at LLNL as part of the effort to understand and measure the cross sections and wavelengths of highly charged ions. In this paper we discussed some of the early history of EBIT and how it was used to help in the development of X-ray lasers. EBIT's capability was unique and we showed some of the experimental results obtained over the years that were done related to X-ray lasers. As X-ray lasers have now become a table-top tool we showed some new areas of research that involve understanding the index of refraction in partially ionized plasmas and suggested new experiments that EBIT may be able to do.

\section{Acknowledgments}

The author would like to thank Dan Dietrich, Ross Marrs, Pat Egan, and K. T. Cheng for helpful discussions on the early history of EBIT and Peter Beiersdorfer for inviting him to present this work at the $20^{\text {th }}$ Anniversary EBIT workshop in Berkeley in November 2006. Work performed under the auspices of the US Department of Energy by the University of California Lawrence Livermore National Laboratory under Contract No. W-7405-Eng-48.

\section{References}

1. Clarence A. Robinson, Jr., “Advance made on high-energy laser," Aviation Week \& Space Technology, pp. 25-27 (February 23, 1981)

2. J. Nilsen, "Legacy of the X-ray Laser Program," Lawrence Livermore National Laboratory report UCRL-LR-114552 (August 6, 1993) See also http://www.llnl.gov/tid/lof/documents/pdf/222506.pdf

3. J. Nilsen, "Legacy of the X-ray Laser Program," Lawrence Livermore National Laboratory report UCRL-52000-94-11 in Energy \& Technology Review p. 13-21 (November 1994) See also http://www.llnl.gov/etr/11.94.html or http://wxww.1lnl.gov/etr/pdfs/11_94.2.pdf

4. J. Nilsen, Quantum Electronics (Kvantovaya Elektronika) 33, 1 (2003).

5. D. L. Matthews, P. L. Hagelstein, M. D. Rosen, M. J. Eckart, N. M. Ceglio, A. U. Hazi, H. Medecki, B. J. MacGowan, J. E. Trebes, B. L. Whitten, E. M. Campbell, C. W. Hatcher, A. M. Hawryluk, R. L. Kauffman, L. D. Pleasance, G. Rambach, J. H. Scofield, G. Stone, and T. A. Weaver, Phys. Rev. Lett. 54, 110 (1985).

6. E. N. Avrorin, V. A. Lykov, P. A. Loboda, and V. Yu. Politov, Laser and Particle Beams 15, 3 (1997). 
7. M. A. Levine, R. E. Marrs, J. N. Bardsley, P. Beiersdorfer, C. L. Bennett, M. H. Chen, T. Cowan, D. D. Dietrich, J. R. Henderson, D. A. Knapp, A. Osterheld, B. M. Penetrante, M. B. Schneider, and J. H. Scofield, Nucl. Instr. and Meth. B43, 431- 440 (1989).

8. G. A. Chandler, M. H. Chen, D. D. Dietrich, P. O. Egan, K. P. Ziock, P. H. Mokler, S. Reusch, and D. H. H. Hoffmann, Phys. Rev. A 39, 565 (1989).

9. D. D. Dietrich, A. Simionovici, M. H. Chen, G. A. Chandler, C. J. Hailey, P. O. Egan, P. H. Mokler, S. Reusch, and D. H. H. Hoffmann, Phys. Rev. A 41, 1450 (1990).

10. P. Beiersdorfer, M. Bitter, S. von Goeler, S. Cohen, K. W. Hill, J. Timberlake, R. S. Walling, M. H. Chen, P. L. Hagelstein, and J. H. Scofield, Phys. Rev. A 34, 1297 (1986).

11. P. Beiersdorfer at al., Phys. Rev. A 37, 4153 (1988).

12. E. D. Donets, Nucl. Instr. and Meth. B9, 522 - 525 (1985).

13. R. W. Schmeider, C. L. Bisson, S. Haney, N. Toly, A. R. Van Hook, and J. Weeks, Rev. Sci. Instrum. 61, 259 (1990)

14. J. Nilsen, P. Beiersdorfer, K. Widmann, V. Decaux, and S. R. Elliott, Physica Scripta 54, 183 (1996).

15. B. J. MacGowan, M. D. Rosen, M. J. Eckart, P. L. Hagelstein, D. L. Matthews, D. G. Nilson, T. W. Phillips, J. H. Scofield, G. Shimkaveg, J. E. Trebes, R. S. Walling, B. L. Whitten, and J. G. Woodworth, J. Appl. Phys. 61, 5243 (1987).

16. B. J. MacGowan," "X-ray laser research at the Nova laser," SPIE Proceedings 1627- Solid State Lasers III, edited by Gregory J. Quarles (SPIE Press, Bellingham, 2002), pp. 351 - 364

17. J. Nilsen, B. J. MacGowan, L. B. Da Silva, and J. C. Moreno, Phys. Rev. A 48, 4682 (1993).

18. P. Beiersdorfer, J. Nilsen, A. Osterheld, D. Vogel, K. Wong, R. E. Marrs, and R. Zasadzinski, Phys. Rev. A 46, R25 (1992).

19. J. Nilsen, P. Beiersdorfer, S. R. Elliott, and A. L. Osterheld, Physica Scripta 47, 42 (1993).

20. S. Elliott, P. Beiersdorfer, and J. Nilsen, Phys. Rev. A 47, 1403 (1993).

21. S. Elliott, P. Beiersdorfer, and J. Nilsen, Physica Scripta 49, 556 (1994).

22. P. Beiersdorfer, S. R. Elliott, and J. Nilsen, Phys. Rev. A 49, 3123 (1994).

23. J. Nilsen, P. Beiersdorfer, S. R. Elliott, T. W. Phillips, B. A. Bryunetkin, V. M. Dyakin, T. A. Pikuz, A. Ya. Faenov, S. A. Pikuz, S. von Goeler, M. Bitter, P. A. Loboda, V. A. Lykov, and V. Yu. Politov, Phys. Rev. A 50, 2143 (1994).

24. J. Nilsen, S. R. Elliott, and P. Beiersdorfer, J. Phys. B 27, 4523 (1994).

25. P. Beiersdorfer, J. Nilsen, J. H. Scofield, M. Bitter, S. von Goeler, and K. W. Hill, Physica Scripta 51, 322 (1995).

26. S. R. Elliott, P. Beiersdorfer, and J. Nilsen, Phys. Rev. A 51, 1683 (1995).

27. S. R. Elliott, P. Beiersdorfer, B. J. MacGowan, and J. Nilsen, Phys. Rev. A 52, 2689 (1995).

28. I. Yu. Skobelev, A. Ya. Faenov, V. M. Dyakin, H. Fiedorowicz, A. Bartnik, M. Szczurek, P. Beiersdorfer, J. Nilsen, and A. L. Osterheld, Phys. Rev. E 55, 3773 (1997).

29. A. E. Siegman, Lasers, (University Science Books, Mill Valley, California, 1986) pp. 123 125

30. J. Nilsen and E. Chandler, Phys. Rev. A 44, 4591 (1991). 
31. R.F. Smith, J. Dunn, J. Filevich, S. Moon, J. Nilsen, R. Keenan, V.N. Shlyaptsev, J.J. Rocca, J.R. Hunter, and M.C. Marconi, Phys. Rev E 72, 036404 (2005).

32. J. Filevich, J. J. Rocca, M. C. Marconi, R. F. Smith, J. Dunn, R. Keenan, J. R. Hunter, S. J. Moon, J. Nilsen, A. Ng, and V. N. Shlyaptsev, Appl. Opt. 43, 3938 (2004).

33. J. Nilsen and J. H. Scofield, Opt. Lett. 29, 2677 (2004).

34. J. Filevich, , J. J. Rocca, M. C. Marconi, S. Moon, J. Nilsen, J. H. Scofield, J. Dunn, R. F. Smith, R. Keenan, J. R. Hunter, and V. N. Shlyaptsev, Phys. Rev. Lett. 94, 035005 (2005).

35. J. Nilsen and W. R. Johnson, Appl. Opt. 44, 7295 (2005).

36. J. Nilsen, W. R. Johnson, C. A. Iglesias, and J. H. Scofield, J. Quant. Spectrosc. Radiat. Transfer 99, 425 (2006).

37. J. Filevich, J. J. Rocca, M. C. Marconi, S. J. Moon, J. Nilsen, J. H. Scofield, J. Dunn, R. F. Smith, R. Keenan, J. R. Hunter, and V. N. Shlyaptsev, J. Quant. Spectrosc. Radiat. Transfer 99, 165 (2006).

38. J. Filevich, J. Grava, M. Purvis, M. C. Marconi, J. J. Rocca, J. Nilsen, J. Dunn, W. R. Johnson, Phys. Rev. E 74, 016404 (2006).

39. H. R. Griem, Principles of Plasma Spectroscopy, (Cambridge University Press, Cambridge, 1997) p. 9

40. W. R. Johnson, C. Guet, and G. F. Bertsch, J. Quant. Spectrosc. Radiat. Transfer 99, 327 (2006).

41. I. P. Grant, B. J. McKenzie, P. H. Norrington, D. F. Mayers, and N. C. Pyper, Comput. Phys. Commun. 21, 207 (1980). 


\section{Figures}

Fig. 1. Energy level diagram (not to scale) showing the He- $\alpha$ line of Ar resonantly photopumping Ne-like $Y$ and creating gain on the $155 \AA$ laser line. Some select radiative decay rates, in $\mathrm{nsec}^{-1}$, are denoted by $\mathrm{R}$.

Fig. 2. Spectra of the $n=2 \rightarrow 1$ lines in Ar and the Ne-like $Y\left(2 p_{1 / 2}\right) 5 d_{5 / 2}(J=1)$ to ground state line. Ar lines $\mathrm{w}, \mathrm{x}, \mathrm{y}$, and $\mathrm{z}$ have the upper states $1 \mathrm{~s} 2 \mathrm{p}{ }^{1} \mathrm{P}_{1}, 1 \mathrm{~s} 2 \mathrm{p}{ }^{3} \mathrm{P}_{2}, 1 \mathrm{~s} 2 \mathrm{p}{ }^{3} \mathrm{P}_{1}$, and $1 \mathrm{~s} 2 \mathrm{~s}$ ${ }^{3} \mathrm{~S}_{1}$, respectively.

Fig. 3. Optical constant $\mathrm{f}_{1}$ versus photon energy calculated by the average atom code for a $\mathrm{Ag}$ plasma with an ion density of $10^{20} \mathrm{~cm}^{-3}$, a temperature of $4 \mathrm{eV}$, and $\mathrm{Z}^{*}=2.08$. 


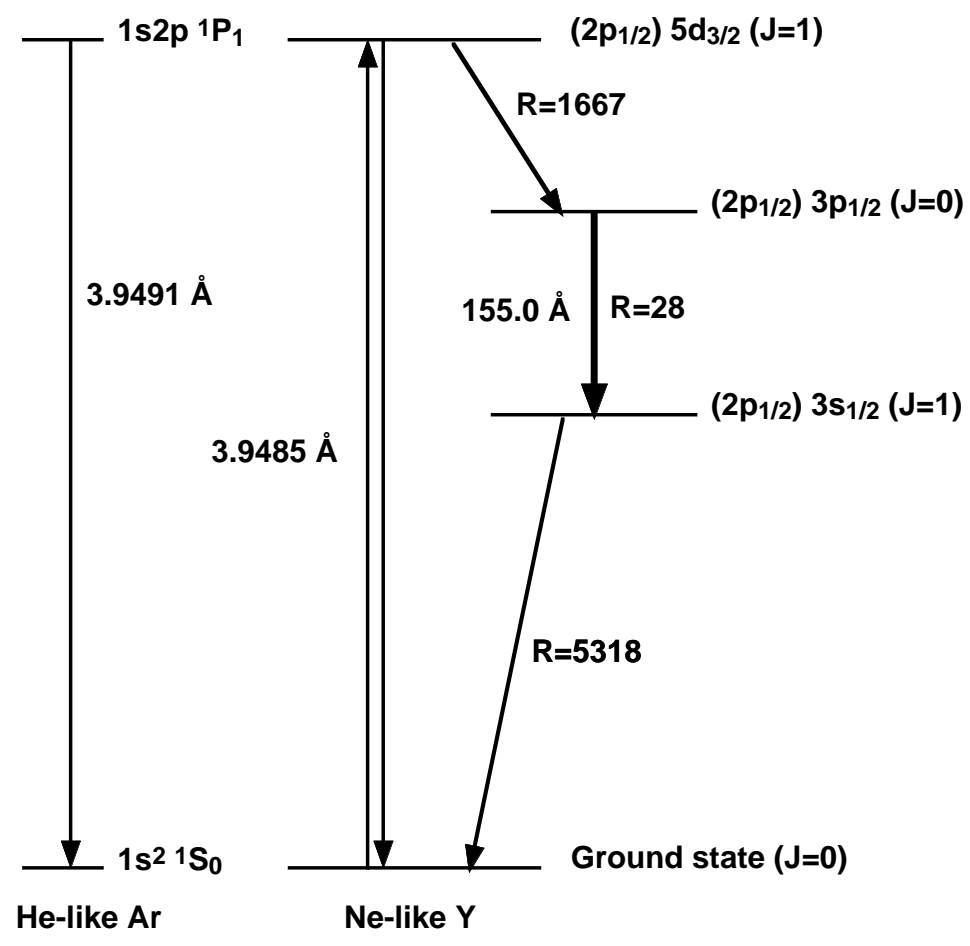

Fig. 1. Energy level diagram (not to scale) showing the He- $\alpha$ line of Ar resonantly photopumping Ne-like $\mathrm{Y}$ and creating gain on the $155 \AA$ laser line. Some select radiative decay rates, in $n \sec ^{-1}$, are denoted by $\mathrm{R}$. 


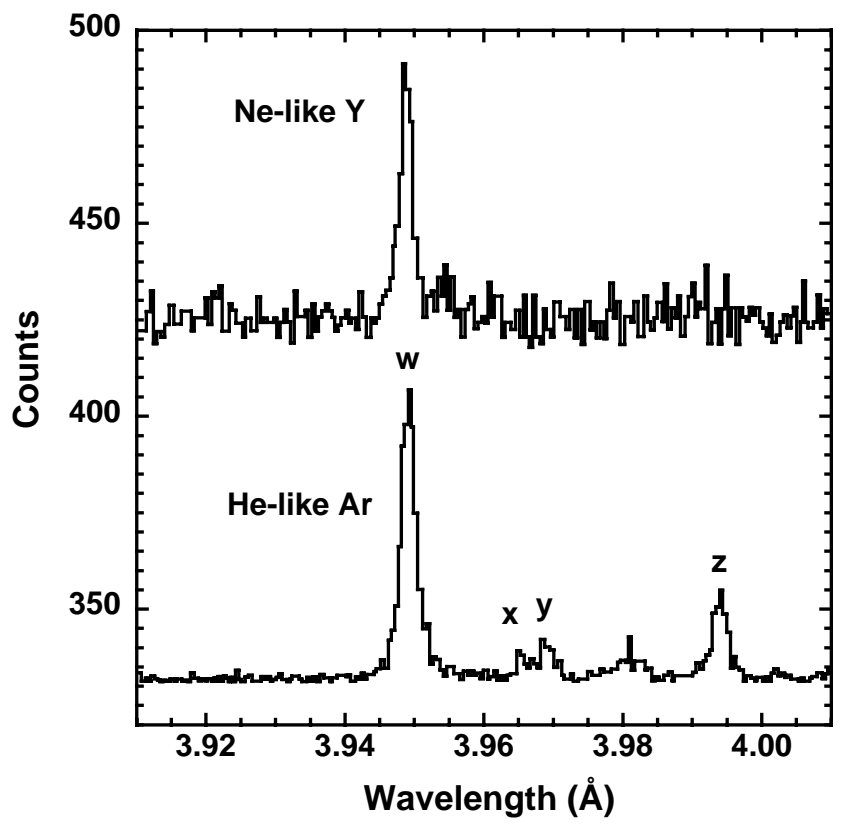

Fig. 2. Spectra of the $n=2 \rightarrow 1$ lines in Ar and the Ne-like $Y\left(2 p_{1 / 2}\right) 5 d_{5 / 2}(J=1)$ to ground state line. Ar lines $w, x, y$, and $z$ have the upper states $1 \mathrm{~s} 2 \mathrm{p}^{1} \mathrm{P}_{1}, 1 \mathrm{~s} 2 \mathrm{p}^{3} \mathrm{P}_{2}, 1 \mathrm{~s} 2 \mathrm{p}^{3} \mathrm{P}_{1}$, and $1 \mathrm{~s} 2 \mathrm{~s}$ ${ }^{3} \mathrm{~S}_{1}$, respectively. 


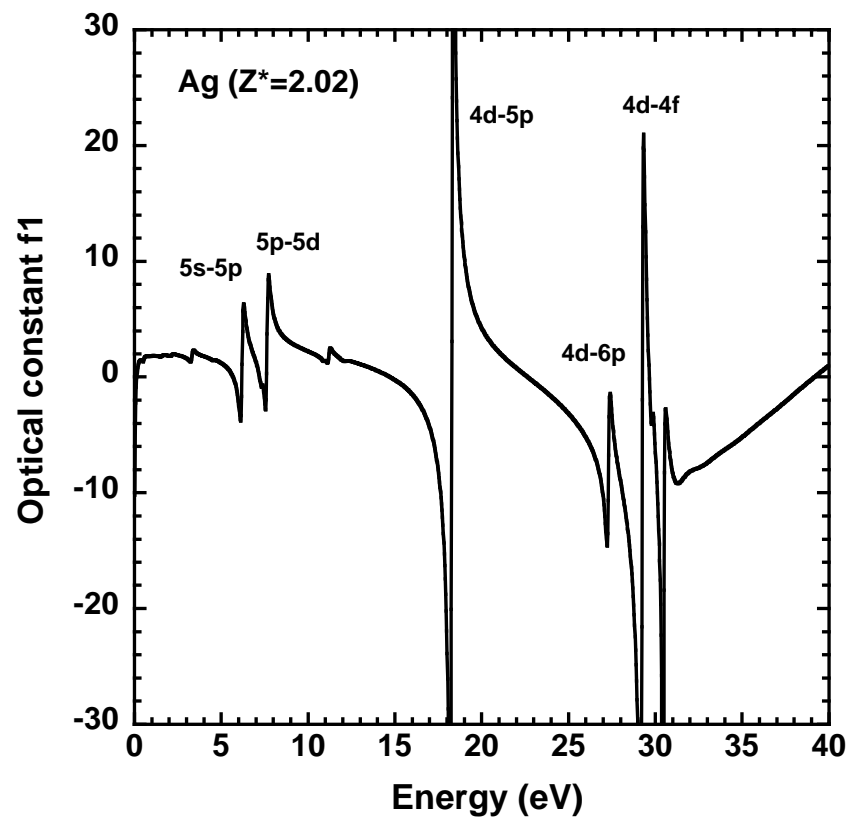

Fig. 3. Optical constant $f_{1}$ versus photon energy calculated by the average atom code for a $\mathrm{Ag}$ plasma with an ion density of $10^{20} \mathrm{~cm}^{-3}$, a temperature of $4 \mathrm{eV}$, and $\mathrm{Z}^{*}=2.08$. 